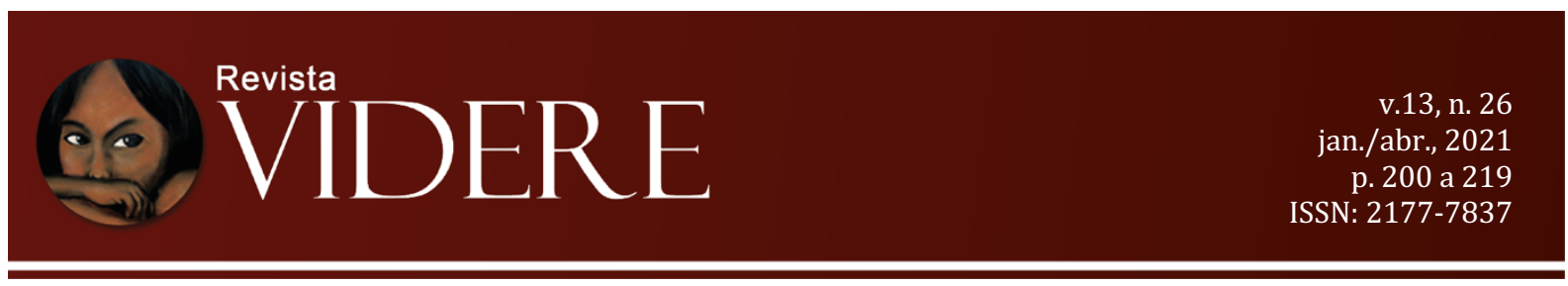

\title{
JUSDIVERSIDAD, TERRITORIOS Y NATURALEZA EN LAS LUCHAS CULTURALES DEL PACÍFICO EN COLOMBIA ${ }^{1}$
}

\author{
Jusdiversidade, territórios e natureza nas lutas culturais do Pacífico na \\ Colômbia
}

\section{Jusdiversidad, territories and nature in the cultural struggles of the Pacific in Colombia}

\author{
Rosembert Ariza Santamaría \\ Doctor en Sociología Jurídica - Universidad Externado de Colombia \\ Profesor Asociado - Departamento de Sociología - Universidad Nacional de Colombia \\ rarizas@unal.edu.co
}

\begin{abstract}
"O estudo da história das lutas de libertação demonstra que são em geral precedidas por uma intensificação das manifestações culturais, que se concretizam progressivamente por uma tentativa, vitoriosa ou não, da afirmação da personalidade cultural do povo dominado como ato de negação da cultura do opressor. Sejam quais forem as condições de sujeição de um povo ao domínio estrangeiro e a influência dos fatores económicos, políticos e sociais na prática desse domínio, é em geral no facto cultural que se situa o germe da contestação, levando à estruturação e ao desenvolvimento do movimento de libertação.

Cabral, 2016 [1970], p. 38)
\end{abstract}

Resumen: Desde la perspectiva de la teoría crítica del derecho se plantea la jusdiversidad como un repertorio de lucha cultural con mayor potencia explicativa que el pluralismo jurídico para comprender la relación de comunidades negras y tradicionales con el territorio y la naturaleza; se retoma metodológicamente en esta investigación la categoría ecosofía popular como es planteada por Manuel zapata Olivella, y los contra lenguajes del pacífico Colombiano como elementos de análisis de la jusdiversidad y resistencia que se realiza al embate global del neoliberalismo. Ellos incorporan el saber ancestral y permiten en medio de las diferentes dinámicas del despojo mantener la cohesión y unidad. El objetivo es establecer el alcance de las décimas, los alabaos, los arrullos, los chagualos y las expresiones culturales del pueblo negro del pacífico frente a la autoprotección colectiva del territorio. Por ello se concluye que la ecosofía popular y la jusdiversidad contribuyen a la convivencia de los afrocolombianos con la naturaleza, a la defensa del territorio, ya que estos saberes transforman e integran las comunidades, haciendo del territorio un espacio vital para realizarse como sujeto colectivo.

Palabras clave: Jusdiversidad. Ecosofía popular. Contra lenguajes. Autoprotección

\footnotetext{
${ }^{1}$ Este trabajo forma parte de los resultados de la estancia posdoctoral realizada en la UnB y al trabajo de campo realizado en Choco, y Cauca en el pacífico colombiano. Agradezco al estudiante Darwin Yessid Cuesta Palacios de la maestría en derechos humanos y democratización de la Universidad externado por el apoyo en la presente investigación.
} 
Resumo: Na perspetiva da teoria crítica do direito, a diversidade é considerada um repertório de luta cultural com maior poder explicativo do que o pluralismo jurídico para compreender a relação das comunidades negras e tradicionais com o território e a natureza; metodologicamente, a categoria ecosofía popular proposta por Manuel Zapata Olivella é retomada metodologicamente nesta pesquisa, e as contra linguagens do Pacífico colombiano como elementos de análise da diversidade da justiça e da resistência realizada ao ataque global do neoliberalismo. Eles incorporam conhecimentos ancestrais e permitem, em meio às diferentes dinâmicas de desapropriação, manter a coesão e a unidade. O objetivo é estabelecer a abrangência dos décimos, dos elogios, das canções de ninar, dos chagualos e das expressões culturais dos negros do Pacífico contra a autoproteção coletiva do território. Por isso, concluise que a diversidade da ecosofía popular e da justiça contribuem para a convivência dos afrocolombianos com a natureza, para a defesa do território, uma vez que esse conhecimento transforma e integra as comunidades, tornando o território um espaço vital a ser percebido como sujeito coletivo.

Palavras-chave: Jusdiversidade. Ecossistema popular. Contra línguas. Autoproteção

Abstract: From the perspective of critical theory of law, diversity is considered as a repertoire
of cultural struggle with greater explanatory power than legal pluralism to understand the
relationship of black and traditional communities with the territory and nature;
methodologically, the popular ecosophy category as proposed by Manuel Zapata Olivella is
taken up methodologically in this research, and the counter languages of the Colombian Pacific
as elements of analysis of justice diversity and resistance carried out to the global onslaught of
neoliberalism. They incorporate ancestral knowledge and allow during the different dynamics
of dispossession to maintain cohesion and unity. The objective is to establish the scope of the
tenths, the praises, the lullabies, the chagualos and the cultural expressions of the black people
of the Pacific against the collective self-protection of the territory. For this reason, it is
concluded that popular ecosophy and justice diversity contribute to the coexistence of Afro-
Colombians with nature, to the defense of the territory, since this knowledge transforms and
integrates communities, making the territory a vital space to be realized as a collective subject.

Keywords: Jusdiversidad. Popular ecosophy. Counter-languages. Self-protection.

\section{Introducción}

Frente al tema de luchas territoriales existen dos perspectivas señaladas por los investigadores de este campo de las ciencias sociales para abordarlo, de un lado los que articulan problemáticas de demandas por tierra "de trabajo" por parte de grupos campesinos fundadas en la tradición de trabajo-familiar y de otros que plantean demandas por territorios identitarios vistos como espacios particulares dotados de peculiaridades asociadas a sus modos de uso material y simbólico.

Para el presente análisis en el caso del pacífico colombiano, asumimos la segunda perspectiva que se retoma para explicar los procesos de resistencia de las comunidades negras en esta parte de la geografía de nuestro continente. 
En lo que respecta a la idea de ecosofía esta surgió dentro del proyecto: Investigación sobre patrones tradicionales de conducta frente al manejo de los recursos naturales renovables en la costa atlántica llevado a cabo por la Fundación Colombiana de Investigaciones Folclóricas dirigida por Manuel Zapata Olivella en su momento. En este trabajo se retoma la ecosofía como elemento constitutivo de la convivencia de los afrocolombianos con la naturaleza en términos de: ecosofía popular, evocando así la fuerte inscripción de lo ecológico en sistemas filosóficos locales como lo señala Zapata Olivella. Aplicando el concepto de ecosofía a las prácticas de comunidades negras del río Baudó, Arocha comenta que:

La relación que los afrobaudoseños crearon con su río, sus quebradas y selvas no sólo era de respeto, sino de hermandad. [...] Así pues, en el Baudó, y quizás en todo el Chocó, entre los afrocolombianos ni las plantas ni los animales existen per se, sino adicionados, complementados y cualificados mediante la palabra, por la mente de las personas $(1999,155-156)$

Esta estructural relación entre naturaleza, territorio y cultura da cuenta de la jusdiversidad, entendida incluso más allá de lo planteado por el profesor Carlos Mares:

Assim como a autodeterminação também os sistemas jurídicos podem ser vistos a partir de ângulos diferentes, isto é, desde um ponto de vista do Estado e desde outro ponto de vista, dos próprios povos. Os Estados afirmam que o Direito é único e estatal, podendo haver normas criadas pelas comunidades e povos, desde que compatíveis com os princípios do Estados e dentro de parâmetros previamente estabelecidos. Entre eles o reconhecimento desta possibilidade pelas leis do Estado. (2016, p. 34)

La jusdiversidad contesta al modelo cultural hegemónico y excluyente, no asume dicha imposición pacíficamente. La jusdiversidad no se agota en el derecho individual, o el derecho colectivo, identifica el valor cultural local de la justicia, la retoma como centralidad identitaria y de defensa del territorio, de la ancestralidad, de la existencia misma.

El pluralismo jurídico es paralelo o concomitante con el derecho estatal, la jusdiversidad, es expresión de prácticas de cuidado de las personas, la naturaleza y sus muertos. Lajusdiversidad no es una pauta legal o normativa, es un elemento de existencia vital presente en los territorios y en los relacionamientos de todo orden.

La pluralidad y el pluralismo jurídico al final pretenden que las expresiones propias de la justicia se incorporen al derecho vigente, o se reconozca por él. La jusdiversidad no pretende ser reconocida, por ello se expresa en la resistencia al poder dominante y propone otra justicia diferente a la del derecho del Estado o el poder instituido. 


\section{Etnización, reconocimiento y lucha legal por el territorio}

Las conquistas realizadas por las comunidades afrocolombianas del pacífico colombiano, son producto de las luchas y reivindicaciones que éstas han librado ante la discriminación, la invisibilidad y el abandono estatal a que han sido sometidas. Las agendas políticas reivindicativas de estas comunidades han surgido como consecuencia del proceso organizativo que se ha construido en los siglos XIX, XX, y XXI, sino desde la resistencia misma a la colonización y esclavitud en el largo siglo XVI.

En el proceso organizativo de las comunidades negras podemos distinguir cinco grandes periodos plenamente diferenciados entre sí, a saber: el periodo de resistencia a la esclavitud que va desde el siglo XVI hasta finales del siglo XIX, el periodo de la Independencia hasta la década del 60 del siglo XX; década de los 70; década de los 80 y por último década de los 90's (WABGOU et al. 2012: 53).

El primer periodo está íntimamente relacionado con el cimarronismo y la creación de palenques como estrategias de resistencia, lucha por la libertad y preservación de la identidad. El segundo, está caracterizado, en términos generales, por la decisiva participación de los negros esclavizados en las guerras independentistas con el fin de ganar por esta vía su libertad ${ }^{2}$ y el surgimiento paulatino y gradual de liderazgos negros que se fueron destacando en el ámbito intelectual y político ${ }^{3}$ (WABGOU et al. 2012: 61-71).

El tercer periodo, que se desarrolla en la década de los 70 , tiene que ver con la incubación de los procesos organizativos afrocolombianos a través de dos espacios: el Primer Encuentro Nacional de la Población Negra Colombiana (1975) y el Primer Congreso de la Cultura Negra de las Américas (1977), los cuales fueron realizados en la ciudad de Cali ${ }^{4}$.

El cuarto periodo está caracterizado, entre otros, por la construcción de un discurso que visibiliza a los afrocolombianos como sujetos políticos, objeto de una especial protección por parte del Estado. Este reconocimiento surge como producto no del papel altruista del Estado, sino a partir de más de diez años de organización y movilización desde los ríos a las ciudades.

\footnotetext{
${ }^{2}$ Este fue lo que prometió Simón Bolívar a los que lucharan de su lado. Sin embargo, éste no cumplió su promesa una vez logrado el objetivo.

${ }^{3}$ Entre los que se encuentran Luis Antonio Robles Suárez (el negro Robles), Manuel Saturio Valencia, Diego Luis Córdoba y Manuel Zapata Olivella, sólo por mencionar algunos.

${ }^{4}$ El primero se llevó a cabo durante tres días $(21,22$ y 23$)$ del mes de febrero del año de 1975 y convocó a 183 delegados de diferentes partes del país a discutir por primera vez en Colombia las problemáticas políticas y sociales de los afrodescendientes. El segundo se llevó a cabo del 24 al 28 de agosto de 1977 y fue un espacio de reflexión y debate entre intelectuales de diversos países africanos, americanos y europeos.
} 
Ese discurso se hace notorio en todos los espacios de participación de los afrodescendientes, como por ejemplo el deporte, la academia (Universidades), sector empresarial (obreros), desde donde se impulsaron procesos organizativos como forma de resistencia y protección, especialmente en la década de los $80 \mathrm{~s}$.

Sobre el particular es importante destacar varios hechos trascendentales en esta época, entre ellos: El nacimiento del proceso organizativo y reivindicativo étnico promovido por grupos estudiantiles universitarios en la Universidad Nacional de Bogotá, la del Cauca en Popayán, y en Cali en las universidades del Valle y Santiago de Cali; El surgimiento en 1982 del Movimiento Nacional por los Derechos Humanos de las Comunidades Afrocolombianas Cimarrón y su pensamiento el Cimarronismo contemporáneo, liderado por Juan de Dios Mosquera. Cimarrón se convirtió en la escuela de formación ideológica y organizativa para los activistas y promotores del despertar de la conciencia étnica provocado por la Ley 70 de 1993 (MOSQUERA JUAN DE DIOS, 2001).

De igual manera se destaca para este periodo el surgimiento de las primeras organizaciones afrodescendientes en el departamento del Chocó, como la Asociación Campesina Integral del Atrato ACIA en Quibdó, la asociación campesina del Alto San Juan ACADESAN, y la Organización de Barrios Populares OBAPO, entre otras (MOSQUERA JUAN DE DIOS, 2001).

Como ejemplos de acciones de resistencia en esta etapa, se puede mencionar, las impulsadas por la creciente organización de la ACIA, que en 1987 demandó la extracción irracional de madera en los territorios habitados ancestralmente, logrando que CODECHOCO 5 formalizara una reserva de 600 mil has, para la implementación de un plan de manejo integral de base (VILLA, 1999, p. 20); la realización de masivas protestas y movilizaciones cívicas que lograron impacto nacional, reclamando la dotación de servicios públicos y la atención y presencia presupuestal del gobierno nacional, deben recordarse el paro cívico departamental del Chocó en 1987; y la presencia masiva de líderes afros en las direcciones regionales y nacionales del movimiento sindical colombiano, especialmente, en los sectores portuarios, ferrocarrileros, bananero, azucarero, y en las juntas directivas de las UTC, CTC, la CSTC, entre ellos se destacaron Tulio Cuevas, José Raquel Mercado y Pastor Pérez (Mosquera Juan de Dios, 2001).

El último periodo histórico caracterizado por Wabgou et al., (2012) está marcado por dos hechos jurídico-políticos que transformaron la vida de los afrocolombianos en el país: la

\footnotetext{
${ }^{5}$ Corporación Autónoma Regional Para el Desarrollo Sostenible del Chocó.
} 
constituyente de 1991 (la Constitución de 1991) y la Ley 70 de 1993, también conocida como ley de comunidades negras.

Ahora bien, según lo ha planteado Eduardo Restrepo (2004) el proceso de etnización ${ }^{6}$ de la comunidad negra en Colombia no empieza a generarse sino a partir de la segunda mitad de la década de los ochenta hasta 1993, distinguiendo a su vez cuatro fases en este proceso, así: una primera fase que tiene lugar en la primera mitad de los años ochenta sobre el río Atrato como escenario donde, debido a la convergencia de diversos factores, se "destiló" por primera vez una noción y estrategia organizativa de las poblaciones campesinas negras como grupo étnico.

Estrategia surgida en respuesta al constante e intensivo intento de despojar a estas comunidades de las tierras ocupadas por ellas históricamente. En este periodo surge la Asociación Campesina Integral del Atrato (ACIA) que, de acuerdo con Restrepo constituye sin duda “[...] la primera organización en Colombia (y quizás en América) que define la comunidad negra como un grupo étnico, esto es, en términos del derecho a la diferencia cultural de una comunidad definida desde su ancestralidad y alteridad" (2004, p. 272).

La segunda fase del proceso de etnización de la comunidad negra en Colombia gira alrededor de la Constitución Política de 1991. Esta fase a su vez comprende varios momentos descritos por Restrepo (2004):

La Constitución de 1991 es la punta del iceberg de un proceso social y político mucho más general que no se puede circunscribir al plano jurídico ni al institucional. En cuanto a la etnización de comunidad negra, se pueden diferenciar tres momentos en donde la Asamblea Nacional Constituyente (ANC) ocupa un lugar destacado. El primer momento sería el de la pre-ANC, iniciado y estimulado con la convocatoria a la ANC; durante este momento se dieron discusiones en múltiples lugares del país con la intención de definir no sólo los candidatos negros, sino también cuáles serían los términos de los derechos específicos de la gente negra que deberían ser contemplados en la nueva Constitución. El segundo momento comprende el período de las sesiones de la Asamblea Nacional Constituyente. Dado que ningún candidato negro fue elegido, se realizaron incontables actividades en aras de poder concretar derechos de las comunidades negras en la Constitución, a través de los representantes indígenas que habían sido elegidos. Con la sanción del Artículo Transitorio 55 (AT 55), casi al cierre de la Asamblea Nacional Constituyente, se culmina este momento abriendo un importante capítulo en el proceso de etnización de la comunidad negra. El tercer momento está ligado al funcionamiento de la Comisión Especial para Comunidades Negras

\footnotetext{
${ }^{6}$ Restrepo entiende por etnización el proceso mediante el cual una o varias poblaciones son imaginadas como una comunidad étnica. Este continuo y conflictivo proceso incluye la configuración de un campo discursivo y de visibilidades desde el cual se constituye el sujeto de la etnicidad. Igualmente, demanda una serie de mediaciones desde las cuales se hace posible no sólo el campo discursivo y de visibilidades, sino también las modalidades organizativas que se instauran en nombre de la comunidad étnica. Por último, pero no menos relevante, este proceso se asocia a la destilación del conjunto de subjetividades correspondientes. (RESTREPO, 2014).
} 
(CECN) que contemplaba el AT 55, la cual debía redactar un texto de ley que desarrolla dicho Artículo. (RESTREPO, 2004, p. 274).

La tercera fase del proceso de etnización de la comunidad negra está definida por la operativización de los componentes sustantivos de la Ley 70 de 1993, y por la articulación de un proyecto organizativo con pretensiones de alcance nacional basado en los derechos étnicos y en la diferencia cultural de comunidad negra.

De esta manera, aunque se logró casi al final de la asamblea Nacional constituyente, el artículo transitorio 55 fue quizá, el logro más importante jurídicamente hablando para las comunidades negras dentro de la constitución de 1991, pues fue a partir de él que se obligó al Estado colombiano a la creación de la ley 70 de 1993, máximo avance jurídico para estas comunidades desde la abolición legal de la esclavitud en 1851. Por ello afirma Wabgou en otro trabajo:

En conclusión, lo que se configura desde la Asamblea Nacional Constituyente y hasta la Ley 70 de 1993 es una definición étnica que encarna un proceso político que, por ende, trae como resultado la aparición de un "nuevo" sujeto político en el escenario nacional. Este sujeto, que es nuevo políticamente hablando, mas no social, económica y culturalmente, asume la difícil tarea de pensarse y relacionarse desde su alteridad, sabiendo que para hacer extensivas sus garantías y derechos se ampara jurídicamente en el marco de una nación que se declara multiétnica y pluricultural, pero que, al mismo tiempo, conserva una cultura política que no está del todo habituada a pensar el poder desde la diversidad étnica (WABGOU et al., 2009, p. 35).

De esta manera, la Ley 70 de 1993 o ley de negritudes marca un punto de quiebre en la lucha por la visibilidad institucional y política de las negritudes en Colombia en la medida que en ningún otro momento histórico se había configurado un contexto político y social tan favorable para promover y concretar un proceso de mayor toma de conciencia de la etnia negra (etnización de las poblaciones negras), como lo fue la década de los años 90.

De acuerdo con Castillo la ley 70 perseguía tres objetivos:

En primer lugar, reconocer el derecho de propiedad colectiva de la tierra a las comunidades negras que ancestralmente han ocupado las zonas rurales ribereñas de la cuenca del Pacífico. En segundo lugar, proteger la identidad cultural y los derechos de las comunidades negras como grupo étnico. En tercer lugar, fomentar el desarrollo económico y social para garantizar a estas comunidades la igualdad de oportunidades con el resto de la sociedad colombiana (2007, p. 209)

El reconocimiento y constitución de un trámite para la protección colectiva de las comunidades negras en Colombia, ha sido uno de los factores más significativos en términos de protección del territorio ancestral, puesto que, dadas las condiciones de inembargabilidad, imprescriptibilidad, e inalienabilidad que por disposiciones constitucionales y legales ostentan los mismos, constituyen limitaciones solidas ante la intensión y puestas de foráneos por 
acaparar dichos territorios. En el Departamento del Chocó, por ejemplo, más del $90 \%$ del territorio de comunidades negras ya fue reconocido y titulado colectivamente.

De ahí que, en los últimos tiempos en el departamento del Chocó, la lucha y resistencia de la población no está centrada en el reconocimiento y titulación, si no en que se garantice el uso, goce y disfrute libremente del territorio, acorde con las prácticas culturales y ancestrales de la población. Uso y goce del territorio que han sido afectados de manera considerable por el conflicto armado, pues paradójicamente las bondades naturales y de localización de las comunidades negras del pacifico son atractivos para los grupos armados al margen de la ley, lo que lleva a su confluencia generando el terror para las comunidades.

Es por ello por lo que la última fase del proceso de etnización descrita por Restrepo (2004) está marcada por los contornos del conflicto y específicamente el desplazamiento que empiezan a transformar las realidades rurales-regionales e invita a repensar y reinventar el sujeto sociopolítico de la etnicidad afrocolombiana.

De esta manera, hay que precisar también que una tipología de resistencia de las comunidades afros en el pacífico, es precisamente la resistencia al conflicto armado que por más de varias décadas ha venido afectando de manera progresiva sus derechos territoriales y con ello transformando sus formas de vida. Respecto a este punto vale la pena destacar el refugio que han encontrado las comunidades en organizaciones no gubernamentales y religiosas como forma de protección y resistencia, entre ellas es importante destacar el trabajo de las pastorales $^{7}$ católicas, que "independientemente" de su rol evangelizador han acompañado e impulsado gestas en pro de las comunidades, los acompañan en sus movilizaciones, visibilizan la problemática de las comunidades a través de comunicados y denuncias públicas entre otras acciones.

Se destacan las protestas y movilizaciones sociales en contra del conflicto y actores armados en el territorio, las cuales no solo se hacen en los cascos urbanos de cabeceras municipales, sino también navegando los ríos o diferentes sectores de confluencia de estos actores. Ejemplo de esto son las movilizaciones por los ríos Atrato "Atratiando", 20038; y Baudó "Baudoseando", 20169, en la que centenares de chocoanos acompañados por

\footnotetext{
${ }^{7}$ Diócesis de Quibdó, Istmina y Tadó.

${ }^{8}$ Este recorrido fue se llevó a cabo en el río Atrato, liderado por la ACIA con el propósito de hacer pedagogía para la paz en todos los municipios en donde hubo una acogida por todas las zonas del área de influencia de del Consejo Comunitario.

${ }^{9}$ Fue una expedición por toda la cuenca del rio Baudó en aras de visibilizar las problemáticas y buscar salidas conjuntas que garanticen el pleno goce y disfrute de los derechos humanos y territoriales que tienen las comunidades, ante el conflicto armado de esa parte del departamento. BAUDOSEANDO. S.f. Negros e indígenas construyendo juntos. Disponible en: <http://viva.org.co/pdfs/victimas/Propuesta_del_Buadoseando.pdf>, Acceso el: 11 de enero del 2019.
} 
organizaciones sociales y organismos no gubernamentales, se movilizaron pidiendo a los actores armados no más violencia en sus territorios.

Entre algunas de las proclamas o comunicados públicos como formas de resistencia, se destaca la "Declaración por la Vida y la Paz" de $1999^{10}$, tres años antes de la "masacre de Bojayá”, en la cual la población afro e indígena de ese municipio con participación del ente territorial y varias instituciones, entre otras cosas se manifestaron en contra de la violencia propiciada para ese entonces por las FARC, las AUC y el ejército de Colombia. A continuación, se trascribe parte de esta:

Exigimos de los grupos armados (paramilitares y guerrilla):

-Se nos respete el Derecho Supremo a la Vida

-Se nos respete el derecho a vivir en paz

-Se nos respete el derecho como pueblo a vivir nuestra autonomía y ser gestores de nuestro etno-desarrollo

-Se nos respete el derecho que tenemos como población ci-vil a no ser involucrados en el conflicto armado, por tanto, que no entren por ningún motivo a nuestro pueblo

-Se nos respete el derecho que tenemos a la libre movilización

- Se nos respete el derecho que tenemos a no involucrarnos en el conflicto armado (como informantes, colaboradores, financiadores, etc.)

-Se nos respete el derecho a comercializar libremente nuestros productos plátano, madera, arroz, pescado, etc.)

-Se nos respete el derecho a traer nuestros víveres para el sustento

-Se nos respete el derecho a no ser señalados como auxiliadores de un bando o de otro.

No obstante, al llamado de las comunidades, los actores armados continuaron en conflicto, el Estado no adoptó las medidas correspondientes, y en el 2002 ocurre producto de esa confrontación armada entre FARC y AUC la llamada: masacre de Bojayá con la aquiescencia del ejército nacional.

En este sentido, aunque se postula a Colombia como el Estado que en Latinoamérica presenta mayor desarrollo en términos del multiculturalismo (ARIZA, 2015), el avance en esta materia se ha quedado solo en el "reconocimiento" de las comunidades étnicas, debido a que no existen las garantías necesarias para que estas comunidades puedan desarrollar sus propios proyectos de desarrollo en sus comunidades, sino que se han visto sometidas a los embates de los proyectos de desarrollo extractivos, ajenos a sus convicciones y prácticas, por lo cual han debido desarrollar diversas estrategias de resistencia para afrontarlos.

10 HERMANAS AGUSTINAS MISIONERAS, 2001. Declaración por la vida y la paz. Disponible en: $<$ https://bojayaunadecada.files.wordpress.com/2012/03/declaracion-por-la-vida-y-la-paz.pdf $>$, Acceso el: $11 \mathrm{de}$ enero del 2019. 
De esta manera, a pesar de lo logrado en la constitución de 1991 y la ley 70 de 1993 es necesario sostener que la legislación colombiana no logro el pluralismo jurídico en materia de comunidades negras y menos ha hecho tránsito a la materialización de la jusdiversidad del pacifico.

\section{Jusdiversidad: (resistencia oral en las comunidades negras del pacífico colombiano)}

En la Costa del Pacifico colombiano la resistencia se manifestaba sobre todo en el fenómeno del cimarronaje, cuando esclavos negros huían de las minas y plantaciones individualmente o en grupos para formar palenques, sociedades organizadas de cimarrones (ZULUAGA, 1993; ROMERO, 1995). A partir del siglo XVIII surgió otro fenómeno, que era más común en el Pacífico Colombiano que en otras regiones de América Latina, la auto manumisión. Algunos esclavos lograban ahorrar suficiente oro trabajando en las minas en su "día libre" para comprar su libertad. Sin embargo, este proceso podía demorarse varios años y pocos eran capaces de sostener las exigencias de un trabajo físico tan duro y prolongado (ROMERO, 1995).

En ambos casos los negros "libres" se asentaban y dispersaban a lo largo de los ríos bastante lejos de toda actividad minera del sistema colonizador. Después de la abolición oficial del sistema esclavista en 1852, los propietarios blancos de las minas y plantaciones de las tierras bajas del Pacífico Colombiano emigraron desde estas regiones a los centros urbanos de Pasto, Cali y Popayán dándose cuenta de que no podían mantener las estructuras de poder y dominación sobre sus anteriores esclavos ahora en libertad.

Hoy en día uno de los frentes de resistencia de los pueblos negros del pacífico, es su lucha identitaria, por el reconocimiento de su ancestralidad, y la búsqueda de la justicia en medio de la diversidad, en otras palabras, la concreción de la jusdiversidad.

Las identidades se construyen y están íntimamente involucradas con el territorio y el medio en el cual las poblaciones se desenvuelven. De tal forma que, al llegar los grupos negros de esclavos africanos a América, cambiaron o transformaron sus manifestaciones culturales con las cuales se identificaban. El nuevo territorio, las nuevas concepciones religiosas y la interacción con otros grupos étnicos han permitido un desarrollo particular en cuanto a factores culturales y sociales se refiere, y se han recreado otras identidades.

Entre los factores que han formado las llamadas nuevas identidades en los grupos negros del Pacífico, se encuentran la música y los contextos donde se llevan a cabo ciertas prácticas musicales. Algunos autores han considerado que las músicas que recrean los grupos 
negros se deben a la "herencia africana" (FRIEDEMANN, 1988).

Una de las manifestaciones claras de identidad cultural de las comunidades negras del Pacífico es su particular visión y concepción mágico-religiosa presente en sus relaciones sociales, con la naturaleza, con el universo, con los espíritus y lo sobrenatural. Su visión religiosa es la resultante de un proceso profundo de deconstrucción de sus paradigmas autóctonos de identidad como africanos y la recreación de una nueva visión cultural que exigió la adaptación de otras costumbres, de otras condiciones de vida, mediante procesos de sincretismo, reinterpretación y transculturación.

Esta particular visión mágico-religiosa, hereda de la tradición africana muchos aspectos referentes a la salud y la enfermedad y recoge los conocimientos indígenas sobre el poder curativo de las plantas y los métodos para combatir la enfermedad. Integra, además, el aporte cristiano con sus santos y todo su imaginario, así como las prácticas mágicas de las brujas castellanas en sus series de oraciones y conjuros, contribuyendo a la ampliación del sistema simbólico curativo y del sistema simbólico general. Encontramos así, en la curandería de los negros del Pacífico, una influencia africana, indígena y también europea.

En el marco de esta visión mágico-religiosa, la naturaleza, el territorio es un escenario ritual con connotaciones no sólo naturales sino también culturales. La selva, el monte, el río son espacios habitados por los espíritus, las divinidades y los ancestros. Allí están presentes las fuerzas naturales y sobrenaturales con quienes es preciso mantener un diálogo, a quienes hay que tener en cuenta y pedir su permiso a la hora de intervenir.

Entre los negros existe una relación fundamental entre la vida de los seres de la naturaleza y los seres sobrenaturales que viven en la misma naturaleza, es decir una relación entre un mundo mítico espiritual y un mundo natural y cultural, que es mediado por un curandero de la comunidad, que a través de sus actos mágicos que manipulan las plantas y los animales para fines curativos y maléficos, crea todo un ambiente de representaciones simbólicas y metafóricas ritualizadas a fin de ejercer un puente de comunicación y diálogo entre los afrocolombianos, su entorno y su cosmogónica. (RESTREPO, 1997, p. 74)

Así, el territorio para el afro colombiano es un espacio básico para el ejercicio del ser, de la esencia vital que configura el desarrollo de los hombres y mujeres negras en un hábitat que ancestralmente ha sido apropiado y donde se ha desarrollado un proyecto de vida cultural, social, ambiental, político, demográfico, económico y sobre todo espiritual desde una perspectiva particularmente étnica, y dentro de una lógica completamente opuesta a la occidental que basa su relación con la naturaleza en la explotación y el dominio de la misma.

Como afirma Restrepo, existe una forma de conciencia religiosa-ambiental, dada milenariamente entre los indígenas y compartida también por los negros del Pacífico, que ha 
permitido la conservación del ecosistema a partir del desarrollo de una serie de técnicas, saberes y manejos que combinados con las simbolizaciones y las concepciones mágico-religiosas producen una sui géneris práctica de explotación, determinada por la combinación pensamiento religioso-pensamiento ecológico. Es decir que, más allá de una serie de conocimientos técnicos, botánicos y agrológicos, lo importante es el conjunto global de concepciones ecológicas mediadas por una cosmovisión y un entramado religioso que le permite explotar sosteniblemente los recursos naturales y socializar la selva. Restrepo (1997).

Las comunidades siguen gestando estrategias de resistencia, repertorios de lucha, no solo contra la violencia sino también contra los proyectos extractivos en sus regiones y una de esas estrategias fue y sigue siendo las décimas, los cantos y los alabaos como expresión de la tradición oral. De esta manera, "Más que una expresión abstracta, la tradición oral viene a cumplir un papel activo en el proceso de concientización de las comunidades rurales en el Pacífico colombiano “(OSLENDER, 2003 p. 226).

De esta forma, después de la Constitución Políticas de 1991 y de la ley 70 de 1993 la tradición oral no sólo tendría un sentido creativo de lo cultural, sino un sentido político organizativo en sentido jusdiverso:

En los ríos, las gentes con sus cantos, danzas y juegos tienen otros motivos para reunirse, ya no es sólo el encuentro ritual con los Santos o con sus muertos, ahora llega a la reunión el decimero para recordar cómo nació la organización del río, para evocar el viaje que algunos de la comunidad emprendieron hasta Bogotá con el objetivo de enseñar sobre el territorio que luchaban y para contar cómo era la vida de las gentes del Pacífico. Canto y danza se integran en la dimensión del encuentro político, los viejos cuentan la historia del poblamiento del río, en el mapa van marcando los sitios donde se asentaron los primeros mayores, enseñan sobre historias de esclavos y amos, sobre comidas y fiestas del pasado, sobre indios y negros, sobre la historia que en el encuentro es portadora de identidad (VILLA, 1998, p. 444-445 apud OSLENDER, 2003).

Ante los proyectos extractivos que se desarrollar en la región del pacífico, muchas veces, sin el consentimiento de las comunidades y la debida consulta previa, la tradición oral juega el papel de discurso de resistencia de las comunidades. Por ejemplo, el caso de la décima titulada Timbiquí. La décima recrea cual es el destino de los pobladores de las orillas del río Timbiquí en la costa pacífica caucana, donde la explotación del oro aluvial por parte de empresas foráneas ha causado grandes estragos al medio ambiente y al tejido sociocultural: 
Timbiquí estás condenado

Por el oro que tú tienes

A vivir siempre dragado

Por otras gentes que vienen.

Vuelve y repite la historia

Tantos años este río

A causa del desvarío

Ha quedado en la memoria

Se fueron y sólo escoria

Dejaron los que han pasado

$\mathrm{Ni}$ un solo gramo ha quedado

De todo lo que sacaron

Ahora otros llegaron

Timbiquí estás condenado.

Gobierno en falsa modestia

$\mathrm{Va}$ asignando concesiones

No se saben las razones

Que causan tanta molestia

Son tratados como bestias

Los negros por el que viene

Sólo a este le conviene

Lo poco que pudo quedar

Y todo lo van a arrasar

Por el oro que tú tienes.

$\mathrm{Y}$ es que en toda explotación

Del oro por esos ríos

Se forman muy grandes líos

Se olvida la población

Y se daña el corazón

Y se destruye el pasado

Cuando todo hubo acabado

Ellos se marchan sin pena

Es una eterna condena

A vivir siempre dragado.

Y cuál es el beneficio

Y cuál es el desarrollo

Si se llega hasta el meollo

De tremendo sacrifico

Maquinarias sin oficio

Que ya ni motores tienen

Para que otros se llenen

$\mathrm{Y}$ al igual que en el pasado

El oro será llevado

Por otras gentes que vienen ${ }^{11}$.

La tradición oral moviliza la protesta social, denunciando hechos que hacen daño en las comunidades. La jusdiversidad presente en la oralidad de las comunidades negras debe entenderse, entonces, como una posibilidad de articulación política, y de construcción identitaria de los espacios culturales de encuentro en esta zona de Colombia.

${ }^{11}$ Ver: Oslender, (2003, p.230) y Mejia (1994, p.26) 
Entre otras prácticas culturales y espirituales se registran los alabaos - himnos de alabanza - y los arrullos - canciones de cuna - manifestaciones orales sobresalientes de la comunidad negra de la costa pacífica; son cantos funerarios en honor y memoria de los difuntos, que se realizan durante la noche del velorio, la última noche de la novena y al cabo de año, y se ejecutan en medio de las oraciones. Los alabaos expresan el duelo por la muerte de un adulto $\mathrm{y}$, a veces, recuerdan la vida de la persona. Los alabaos de la última noche son una despedida para el espíritu, que hasta ese momento ha estado presente en el novenario. A las cinco de la mañana, cuando concluye el rito mortuorio, se deshace la tumba y el altar arreglado para la ocasión, se apagan las luces y se cierran las puertas y las ventanas; y en este momento el difunto inicia una nueva etapa en su trayectoria existencial. Rito que demuestra el vitalismo espiritual africano que reconoce la presencia e influencia de los difuntos y ancestros en la vida terrenal.

Mary Grueso Romero (1997) en sus cantos funerarios muestra la importancia de la relación con los santos y con la Virgen María. Esta cercanía e intimidad a los seres celestiales restaura el equilibrio vital e instaura nuevas relaciones de parentesco; las ya mencionadas líneas de parentesco ancestral y sobrenatural con los santos, que son indispensables para proyectarse en el futuro y para recobrarlos lazos familiares rotos con la esclavitud; así, los afrocolombianos recuperan el pasado y se proyectan al futuro, al trazar puentes entre el pasado y el presente.

El alivio es también un canto fúnebre ejecutado por mujeres en las noches de los velorios para "animar las almas de los difuntos" (MARTíNEZ DE PEÑA, 1999, p. 89). "A la Virgen del Carmen" es un alivio de Mary Grueso en el que son claras las influencias del catolicismo. Y es notable como el hermano muerto es ya un intermediario entre cielo y tierra, y puede interceder por los pecadores que deja atrás. La persona que muere obtiene, así, un estatus especial en la familia y también crea un puente entre presente y futuro.

\footnotetext{
Aquí en medio de esta sala con cuatro velas está este hermano tan querido y no lo puedo evitá. (bis) Pongámosle el rosario para que él lo pueda rezá por todos los pecadores que en esta tierra están. (Este yo que sí soy yo, Mary Grueso)
}

Sin duda alguna la tradición oral y los cantos religiosos han sido un vehículo de resistencia y de apoyo espiritual para las comunidades afrocolombianas en su largo proceso de defensa del territorio y la vida en el litoral pacífico. 


\section{Ecosofía popular y jusdiversidad}

La ecosofía popular es práctica y método de la jusdiversidad, se entiende como un elemento constitutivo de la convivencia de los afrocolombianos con la naturaleza, evocando así la fuerte inscripción de lo ecológico en sistemas filosóficos locales como lo señala Manuel Zapata Olivella en varios de sus reflexiones. La ecosofía popular es un modo de estar en el mundo, de percibirlo. Un saber práctico que transforma la conciencia e integra la unidad de la vida, haciendo del sujeto-objeto-medio un continuo (ZAPATA, 1989).

Desde la ecosofía popular, la espiritualidad y la jusdiversidad, los pueblos negros del pacífico enfrentan la lucha por la vida, por el territorio y la subsistencia. Desde estos saberes y otros construyen día a día las formas propias de protección y autoprotección colectiva del territorio. Pero la base de dichas estrategias de subsistencia está marcadas y pautadas por la conciencia sobre el territorio, y todo lo que él implica.

En su novela Changó el gran putas Zapata Olivella, parte como centro de su estructura narrativa del Muntu. Este concepto contempla la coexistencia de seres humanos, animales, plantas, minerales y los objetos que sirven al hombre. Sobre el Muntu, Mina (2003) sostiene que "hay una interacción siempre presente entre todos los reinos y las criaturas de la tierra, que se extiende a aquello que no alcanzamos a percibir" (p. 133).

En un proceso de ecosofía y jusdiversidad en el pacífico con comunidades afrocaucanos del municipio de Guapi ${ }^{12}$ (Consejo Comunitario de Comunidades Negras del Río Guajuí) se realizaron diferentes exploraciones de las prácticas ancestrales para identificar en ellas, las que potencialmente pueden contribuir a mejorar la situación de seguridad del territorio $\mathrm{y}$ activar respuestas de protección pertinentes frente a los riesgos que se enfrentan. $\mathrm{Y}$ es precisamente desde el Muntu y la espiritualidad que se constituye la base del sistema de autoprotección comunitaria del río Guajuí.

Este proceso permitió construir colectivamente una ruta de autoprotección colectiva, desde el reconocimiento de prácticas ancestrales centradas en la relación Cultura- Territorio, que hacen posible la correlación de los procesos de ancestralidad, sujeto colectivo e identidad, los cuales están en la base del fortalecimiento de capacidades del tejido social y asociativo; es decir, en los vínculos comunitarios de los habitantes del río Guajuí.

En esta perspectiva se asume que las prácticas culturales (los cementerios, las trenzas, la pesca, la minería, el trapiche, el potrillo, el bombo, el cununo, el baile) etc., presentes en la

\footnotetext{
${ }^{12}$ Proyecto actualmente en curso ejecutado por PAS y PI con el apoyo de Cococauca en el municipio de Guapí
} (2018-2019) del cual el autor del presente texto es Asesor. 
vida cotidiana contienen la posibilidad de construir estrategias de autoprotección - protección colectiva. De allí que se simbolice esta ruta con la imagen de la atarraya y se nombre con la expresión: Atarrayando la protección y la potenciación de la vida en la costa pacífica caucana.

Uno de los aportes centrales de este proceso es la construcción del enfoque de protección colectiva intercultural y territorial que es comprendido como un marco ético y comunitario que teje las relaciones sociales, culturales, espirituales y políticas del consejo comunitario del rio Guajuí. Así la ruta de auto protección se constituye desde el enfoque de protección colectiva, y asume al territorio y la territorialidad como centro de la protección colectiva, reconoce como sujeto a la comunidad afro-caucana que realiza su proyecto vital en este territorio y considera adicionalmente a las familias y sus parientes como los principales encargados del cuidado y protección del territorio.

El enfoque se aborda como ya se dijo desde la ancestralidad, la cultura propia del rio Guajuí, la vivencia del territorio, la identidad afro-caucana, y sus prácticas. Desde este abordaje se constituyen y reconstituyen los vínculos y relaciones colectivas de protección y seguridad colectiva del territorio, con todas las presencias del adentro y afuera comunitario, junto a las fortalezas del sujeto colectivo, que permita la realización vital de todos sus miembros, con sus recursos naturales, su espiritualidad y el respeto y garantía de los derechos del territorio, los derechos ancestrales y los derechos humanos de la comunidad afro-caucana.

Este enfoque de protección colectiva (EPC), por supuesto se basa en el enfoque de derechos y por ello reconoce los derechos humanos individuales y colectivos como reclamos ante los titulares de obligaciones. Se centra en las causas estructurales de los problemas y sus manifestaciones.

El elemento de protección colectiva se comprende como los vínculos, relaciones y redes de solidaridad colectivas que en la dinámica cultural propia del rio Guajuí garantiza la seguridad y protección colectiva del territorio. Este elemento se constituye desde las relaciones de parentesco, o familia extensa, fundamento de la autoprotección y la resistencia.

La ruta de autoprotección colectiva es entonces un esfuerzo colectivo, que parte del contexto de disputa de diferentes actores por el territorio, la experiencia de resistencia y defensa de la vida de los miembros del consejo comunitario del río Gujauí, y los contenidos y elementos de la ruta son la prueba de las múltiples formas ancestrales desarrollas para pervivir y conservar el territorio desde las comunidades negras que los conviteros ${ }^{13}$ y conviteras en las múltiples horas de trabajo, reflexión y análisis permitieron materializar.

\footnotetext{
${ }^{13}$ Conocida como guardia cimarrona en otros consejos comunitarios de comunidades negras del pacífico. Personas de la comunidad que prestan el servicio de cuidado del territorio y guardianes de la naturaleza.
} 


\section{Conclusiones}

En el pacífico colombiano, a pesar de la guerra civil, del narcotráfico, de los distintos niveles de despojo implementados por las multinacionales, como del propio Estado y de una permanente amenaza y cultivo del miedo para desplazar a las comunidades negras ellas persisten y resisten en el territorio.

Tal vez una de las actividades con mayor impacto en la costa pacífica es la minería, ella genera notorios cambios en los territorios y las comunidades donde se practica, independientemente de la manera como se desarrolle, de gran escala o pequeña escala, de manera lícita o de forma ilegal, lo que menos ha dejado ha sido desarrollo social y económico, esto se evidencia en el trabajo investigado por el Observatorio Pacífico y Territorio (2018). Varias situaciones relacionadas con esta práctica evidencia que la calidad de vida de los pueblos del Pacífico colombiano, tanto afros, indígenas y mestizos, en lugar de tener una mejoría, existe una pérdida considerable en la satisfacción de los derechos individuales y colectivos, entre esos se encuentra: un agotamiento en la legitimidad y en la autoridad tradicional; un aumento de la pobreza y disminución del acceso a un trabajo digno; altos niveles de violencia, afectaciones a la salud; por último, un deterioro del medio natural, es decir, afectaciones a los recursos inagotables, renovables y no renovables.

Frente a esta apabullante realidad el pueblo negro del litoral pacífico colombiano, continua desde sus prácticas ancestrales defendiendo y protegiendo sus recursos naturales, sin desconocer que la guerra, la minería y el narcotráfico son hoy los mayores flagelos dentro de los territorios.

Las décimas, los alabaos, los arrullos, los chagualos y todas las expresiones culturales de los pueblos negros del pacífico tiene una connotación de resistencia. Ellos incorporan el saber ancestral y permiten en medio de las diferentes dinámicas del despojo mantener la cohesión y unidad.

La ecosofía popular y la jusdiversidad son elementos que contribuyen a la convivencia de los afrocolombianos con la naturaleza, a la defensa del territorio, con estos saberes prácticos se transforman e integran las comunidades, haciendo del territorio un espacio vital para realizarse como sujeto colectivo.

Procesos de comunidades negras como la ruta de autoprotección colectiva, realizados desde las prácticas ancestrales, construyen sujeto colectivo e identidad, los cuales están en la base del fortalecimiento de capacidades del tejido social y asociativo y por supuesto coadyuva a los procesos de resistencia. 
En esta perspectiva se asume que las prácticas culturales (los cementerios, las trenzas, la pesca, la minería, el trapiche, el potrillo, el bombo, el cununo, el baile) etc., presentes en la vida cotidiana contienen la posibilidad de construir estrategias de autoprotección - protección colectiva.

Es dramático el número de líderes sociales y defensores asesinados en Colombia en el último período, y nadie parece tener la respuesta o responsabilidad frente a la protección y garantía a la vida de los defensores rurales de derechos humanos de comunidades negras en el pacífico, por ello este canto de conviteras del Río Guajuí, comunidad de Limones en un encuentro sobre protección colectiva en Guapí, Cuaca en Julio de 2018, retrata otra vez la realidad:



\section{BIBLIOGRAFÍA}

ARBOLEDA, Santiago. Le han florescido nuevas estrellas al cielo. Suficiencias íntimas y clandestinización del pensamento afrocolombiano. Cali: Editorial Poemía, 2016.

AROCHA, Jaime. Ombligados de Ananse. Hilos ancestrales y modernos en el Pacífico colombiano. Bogotá: Universidad Nacional de Colombia, Facultad de Ciencias Humanas (Colección CES), 1999.

ARIZA, Rosembert. El pluralismo jurídico en América Latina y la nueva fase del colonialismo jurídico en los estados constitucionales. Revista InSURgência, Brasilia: vol. 1, n. 1. junio de 2015 
BELTRAN, Yilson. Marxismo ecológico negro. Tabula Rasa. vol. 1, n. 28), enero-uunio, Bogotá, 2018.

CABRAL, Amilcar. (2016) [1970] LIBERTAÇÃO NACIONAL E CULTUR. En: MONDAINI, Marco (Org.). Cultura em tempos de libertação nacional e revolução social: Amílcar Cabral, Samora Machel e Mário de Andrade. Recife: Editorial UFPE.

FRIEDMANN, Nina S. Cabildos negros: refugios de africanía en Colombia. Caracas: Universidad Católica Andrés Bello, 1988.

GRUESO ROMERO, Mary. EI otro yo que sí soy yo. Poemas de amor y mar. Buenaventura: Ediciones Marymar. 1997.

HINESTROZA, Lesneider. Los consejos Comunitarios y su papel en la conservación y protección del medio ambiente. Revista institucional Universidad tecnológica del Chocó v. 24 fasc. p.74, 2006.

HENAO, Darío. Los hijos de Changó, la epopeya de la negritud en América. En: Prólogo. Zapata, M. (Ed.). Changó, el gran putas. Bogotá: Ministerio de Cultura, 2010.

MARTÍNEZ de Peña, María Elba, et al. Rescate cultural desde la producción poética escrita por mujeres del Litoral Pacífico colombiano en la década del noventa, tesis para optar al título de maestría en la Facultad de Educación de la Universidad del Quindío, 1999.

MARTÍNEZ Alier. Conflictos ecológicos y justicia ambiental. Revista Papeles, 103, 11-27, 2008.

Mares de Sousa, Carlos. (2016) En: Estado e Povos na américa latina Plural, Goiania, Edi. da PUC, Goiás.

MINA, William. Dialogando con Manuel Zapata Olivella. Mito, Historia, Cultura, Novela y Etnoeducación. En: MINA, William. Manuel Zapata Olivella: pensador y humanista. Revista Afro-Hispanic Review, vol. 25, n. 1., pp. 149-241, 2006 
MOSQUERA, Juan de Dios. Boletín del Movimiento Nacional Afrocolombiano Cimarrón: Estudios Afrocolombianos.

Disponible

en:

$<$ http://babel.banrepcultural.org/cdm/ref/collection/p17054coll10/id/2755>, Acceso en: 11 de enero del 2019.

OBSERVATORIO PACÍFICO Y TERRITORIO (OPT). Impactos de la minería en el pacífico colombiano. Editorial Nuevo Milenio, 2018

OSLENDER, U. Discursos ocultos de resistencia: tradición oral y cultura política en comunidades negras de la costa pacífica colombiana. Revista Colombiana de Antropología Volumen 39, enero-diciembre, Bogotá, 2003.

RESTREPO, Eduardo. Biopolítica y alteridad: dilemas de la etnización de las colombias negras. En: RESTREPO, Eduardo. Conflicto e (in)visibilidad Retos en los estudios de la gente negra en Colombia de Eduardo Restrepo: ROJAS, Axel. (ed). Editorial Universidad del Cauca. Cali, 2004.

Economía y simbolismo en el Pacifico "negro". Tesis de antropología, Medellín: Universidad de Antioquia, 1997.

ROMERO, Mario. Poblamiento y Sociedad en el Pacífico Colombiano. Siglos XVI al XVIII, Cali: Universidad del Valle, 1995.

WABGOU, Maguemati. Voces de la población afrocolombiana en la localidad de Kennedy. Bogotá: Instituto Unidad de Investigaciones Jurídico-Sociales Gerardo Molina -UNIJUS-, Grupo Migraciones y Desplazamientos, Universidad Nacional de Colombia, 2009ñ

; Arocha, Jaime; Salgado, Aiden; Carabalí, Juan. Movimiento Social Afrocolombiano, Negro, Raizal y Palenquero: El largo camino hacia la construcción de espacios comunes y alianzas estratégicas para la incidencia política en Colombia. Bogotá: Facultad de Derecho, Ciencias Políticas y Sociales. Instituto Unidad de Investigaciones Jurídico-Sociales Gerardo Molina (UNIJUS); Universidad Nacional de Colombia, 2012. 
ZAPATA, Manuel. Las claves mágicas de América (Raza, Clase y Cultura). Bogotá: Plaza y Janés, 1989.

ZULUAGA, Francisco. Cimarronismo en el Sur- Occidente del Antiguo Virreinato de Santafé de Bogotá, en LEYVA, Franco. (ed.), Colombia Pacífico, Vol. 2, Fondo FEN, Bogotá, pp. 421-427, 1993.

Data de recebimento: 19.03.2021

Data de aprovação: 17.04.2021 